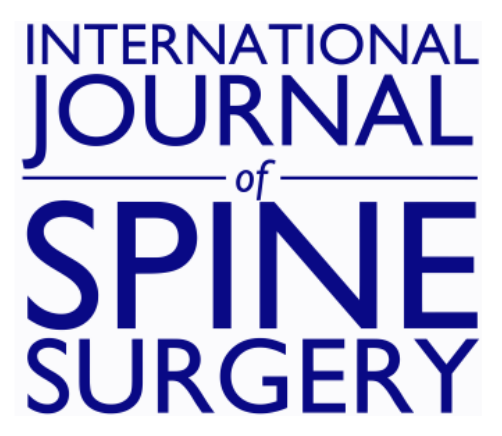

\title{
Degenerative Adult Cervical Kyphosis With Secondary Diagnosis Codes Are Associated With Higher Cost and Complications After Spinal Fusion: A Medicare Database Study
}

Nikhil Jain, Azeem T. Malik, Frank M. Phillips, Safdar N. Khan and Elizabeth Yu

Int J Spine Surg 2021, 15 (1) 26-36

doi: https://doi.org/10.14444/8003

http://ijssurgery.com/content/15/1/26

This information is current as of April 26, 2023.

Email Alerts Receive free email-alerts when new articles cite this article. Sign up at:

http://ijssurgery.com/alerts

The International Journal of Spine Surgery

2397 Waterbury Circle, Suite 1,

Aurora, IL 60504, Phone: +1-630-375-1432 


\title{
Degenerative Adult Cervical Kyphosis With Secondary Diagnosis Codes Are Associated With Higher Cost and Complications After Spinal Fusion: A Medicare Database Study
}

\author{
NIKHIL JAIN, MD ${ }^{1}$ AZEEM T. MALIK, MD,${ }^{1}$ FRANK M. PHILLIPS, MD ${ }^{2}$ SAFDAR N. KHAN, MD, ${ }^{1}$ \\ ELIZABETH YU, MD \\ ${ }^{1}$ The Ohio State University Wexner Medical Center, Columbus, Ohio, ${ }^{2}$ Midwest Orthopaedics at Rush, Rush University, Chicago, Illinois
}

\begin{abstract}
Background: Adult cervical deformity (ACD) is a potentially debilitating condition resulting from kyphosis, scoliosis, or both, of the cervical spine. Conditions such as ankylosing spondylitis, rheumatoid arthritis, Parkinson's disease, and neuromuscular diseases are particularly known to cause severe deformities. We describe the 90-day cost and complications associated with spinal fusion for ACD using International Classification of Diseases (ICD) coding terminology and study if secondary diagnoses associated with potential for severe deformity affect the cost and complication profile of ACD surgery.

Methods: Medicare data were used to study hospital costs and complications within 90 days after primary cervical fusion for ACD in 2 cohorts matched by demographics and comorbidity burden: (1) patients with diagnoses of secondary pathology (SP) known to cause severe deformity and (2) without SP. Univariate and multiple-variable analyses to study incidence of complications, readmission, and costs within 90 days were done.

Results: A total of 2900 patients in matched cohorts of 1450 each were included. The mean index hospital payment (\$26 $545 \pm \$ 25968$ versus \$22 $991 \pm \$ 21599)$ and length of stay (4.8 \pm 5.6 versus $3.9 \pm 4.5$ days) was significantly $(P<.01)$ higher in ACD patients with SP. On adjusted analysis, the risk of procedure-related complications was higher (odds ratio $[\mathrm{OR}]=1.47,95 \%$ confidence interval $[\mathrm{CI}], 1.18-1.83$ ) in patients with SP than those without $\mathrm{SP}$, but not readmission $(\mathrm{OR}=1.04,95 \% \mathrm{CI}, 0.82-1.32)$ or refusion $(\mathrm{OR}=0.95,95 \% \mathrm{CI}, 0.45-2.0)$ within 90 days. The cost profile of complications, readmission, and refusion has been given.

Conclusions: ACD patients with secondary diagnosis codes such as inflammatory arthropathy or neuromuscular pathology incur higher 90-day costs due to the inherent requirement of bigger fusions and higher risk of peri-operative complications, but with similar risk of readmission and refusion as those without SP.

Level of Evidence: 3.

Clinical Relevance: With evolving health care reforms and payment models, knowledge of conditions associated with higher expenditure after elective spine surgical procedures will be beneficial to providers and payors for appropriate risk stratification.

Cervical Spine

Keywords: deformity, Medicare, payments, risk stratification
\end{abstract}

\section{INTRODUCTION}

Adult cervical deformity (ACD) is a potentially debilitating condition resulting from kyphosis, scoliosis, or both, of the cervical spine. Cervical kyphosis is more common than scoliosis in the adult population and can lead to myelopathy and poor quality of life. ${ }^{1}$ A wide variety of etiologies can result in ACD, including spondylosis, inflammatory arthropathy, trauma, infection, iatrogenic, neoplastic, and neuromuscular pathology. ${ }^{2,3}$ Conditions such as ankylosing spondylitis, rheumatoid arthritis, Parkinson's disease, and neuromuscular diseases are particularly known to cause severe deformities like "chin-on-chest" or "dropped head syndrome."4-11

Various surgical techniques have been described to manage ACD through the anterior, posterior, or combined approaches. Surgical correction using these techniques requires extensive preoperative planning, patient counselling, and postoperative care. ${ }^{1,12,13}$ Despite improvement in anesthetic and surgical techniques, the comorbid patient popula- 
tion and magnitude of procedure put patients at a high risk of complications and even mortality. ${ }^{1-3,12-16}$ Health care costs associated with thoracolumbar adult spinal deformity (ASD) surgery and its complications have been reported ${ }^{17-20}$; however, no specific reports on the costs of ACD surgery exist. With evolving health care reforms and payment models, understanding expenditure on elective spine surgical procedures, especially those with potential for high costs, will be beneficial. ${ }^{19,20}$

We have performed an analysis of Medicare (2005-2014) data to report the 90-day costs and complications associated with primary cervical fusion for degenerative cervical deformity as diagnosed by International Classification of Diseases (ICD) terminology We have compared costs and complications between 2 matched groups with and without additional diagnoses of inflammatory arthropathy and neuromuscular disorders. The aim of this analysis was twofold: (1) describe costs and complications associated with surgery for ACD, which has not been described before and (2) to study if diagnoses associated with potential for severe deformity affect the cost and complication profile of ACD surgery. Apart from understanding expenditure related to ACD, our results of complication and readmission profile may be beneficial in preoperative patient education and risk stratification.

\section{MATERIAL AND METHODS}

\section{Data Source}

We used the $100 \%$ Medicare Standard Analytical Files comprising of 51 million patients with Medicare parts A and B coverage between 2005 and 2014 for this analysis. Access to these files was obtained on a remote server hosted by PearlDiver (PearlDiver Technologies, Inc., Colorado Springs, CO). ${ }^{21,22}$ Various research capabilities ranging from descriptive to advanced statistical analyses are available through their proprietary software. Custom patient cohorts based on ICD diagnosis and procedure codes, Current Procedural Terminology (CPT), and Diagnosis Related Group codes, discharge status, etc, can be created. Longitudinal tracking based on distinct patient identifiers is offered. Additionally, user queries result in aggregate deidentified data which are HIPAA compliant. Therefore, no institutional review board approval was required before this study.

\section{Patient Sample}

For our analysis, we identified all primary cervical fusions done for degenerative cervical disease in the Medicare population using ICD-9 codes. From this cohort, we created 2 matched groups of patients: first, patients undergoing cervical fusion who had cervical kyphosis and diagnoses of secondary pathology (SP) that are known to cause severe deformity. We included rheumatoid arthritis, ankylosing spondylitis, Parkinson's disease, myasthenia gravis, and muscular dystrophy as possible secondary causes for severe deformity. ${ }^{4-11}$ The second group included patients undergoing cervical fusion who had a diagnosis of cervical kyphosis but did not have abovementioned additional diagnoses. The methodology used for creation of these cohorts has been given in the Figure and Appendix (Table A1). To be as representative as possible, ICD diagnoses of cervical degenerative disease, kyphosis, and SP were searched on the same hospital encounter as the cervical fusion procedure. Final study groups were created by one-to-one patient matching for each of the following variables: age, gender, region, Charlson Comorbidity Index (CCI), and year of surgery. This was done to ensure uniformity in surgical risk profile, regional practices, and cost index while comparing our primary outcome measures between study groups.

\section{Data Collection}

The distribution of patients according to demographics and comorbidity burden using CCI has been described ${ }^{21}$. The approach of fusion as anterior (ICD 81.02), posterior (81.03), combined (81.02 and 81.03 ), and number of levels of surgery as 1-2 level (81.62), 3-7 level (81.63), $\geq 8$ level (81.64) were identified. Fusions extending to the atlantoaxial complex (81.01) and thoracic spine (81.05) were also identified.

\section{0-Day Complications, Readmissions, and Refusion}

A period of 90 days postsurgery is important from a bundled payments, readmission reduction, and quality of care perspective as determined by Medicare. ${ }^{20,23}$ Procedure-related complications such as posthemorrhagic anemia (ICD 285.1), dural tear (998.2), hematoma (998.12), acute respiratory failure (518.81), cardiac (997.1), and nervous system complications (997.09) were recorded. Additionally, 


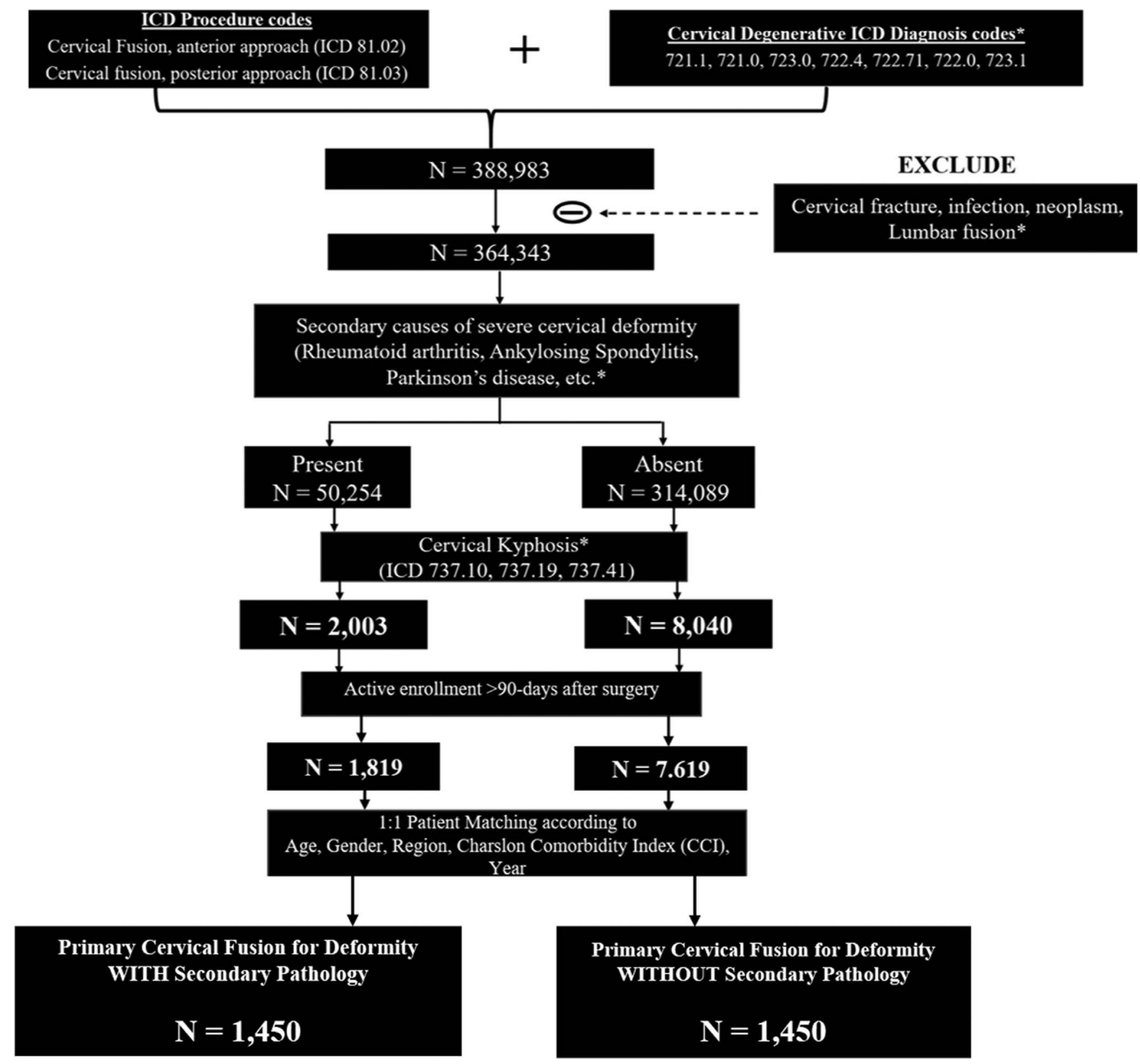

Figure. Flowchart for inclusion or exclusion methodology and creation of matched cohorts of patients undergoing cervical fusion for adult cervical deformity (ACD) with and without secondary pathology (SP), Medicare (2005-2014).

we identified a diagnosis of dysphagia after surgery within 90 days using ICD 787.20, 787.22, 787.18, 787.23, and 787.29. Patients with a preexisting diagnosis of dysphagia were removed from this analysis.

Hospital readmission within 90 days along with their primary diagnosis fields were used to record incidence and cause of readmission. The following categories have been used to report readmissions: wound infection or dehiscence, systemic infection or sepsis, pneumonia, myocardial infarction, urinary tract infection, deep vein thrombosis or pulmonary embolism, and mechanical complications of instrumentation or implant. Finally, the performance of cervical refusion (ICD 81.32, 81.33) within 90 days was identified and reported. A complete list of ICD codes and their descriptions used for recording complications, readmissions, and refusion is given in Appendix (Table A2).

\section{Data Analysis}

Qualitative data have been presented as frequency and percentage and quantitative data as mean 
Table 1. Distribution of patients after matching for age, gender, region, year, and Charlson Comorbidity Index (CCl), cervical fusion for deformity (Medicare 2005-2014).

\begin{tabular}{lc}
\hline Parameter & No. $(\mathbf{\%})$ \\
\hline Total & $1450(100)$ \\
Age, y & \\
$<65$ & $492(33.9)$ \\
$65-69$ & $379(26.1)$ \\
$70-74$ & $315(21.7)$ \\
$75-79$ & $206(14.2)$ \\
$80-84$ & $53(3.7)$ \\
$\geq 85$ & $5(0.3)$ \\
Gender & \\
Female & $953(65.7)$ \\
Male & $497(34.3)$ \\
Region & \\
Northeast & $142(9.8)$ \\
Midwest & $309(21.3)$ \\
South & $683(47.1)$ \\
West & $316(21.8)$ \\
Year & \\
2005 & $109(7.5)$ \\
2006 & $86(5.9)$ \\
2007 & $117(8.1)$ \\
2008 & $120(8.3)$ \\
2009 & $150(10.3)$ \\
2010 & $160(11.0)$ \\
2011 & $180(12.4)$ \\
2012 & $201(13.9)$ \\
2013 & $193(13.3)$ \\
2014 & $134(9.2)$ \\
CCI & \\
2 & $120(8.3)$ \\
3 & $244(16.8)$ \\
4 & $371(25.6)$ \\
5 & $281(19.4)$ \\
6 & $207(14.3)$ \\
7 & $122(8.4)$ \\
8 & $58(4.0)$ \\
$\geq 9$ & $47(3.2)$ \\
\hline & \\
&
\end{tabular}

with standard deviation. Primary outcome variables compared between study groups were complications, readmission, and refusion within 90 days. Univariate comparison of qualitative variables was done by $\chi^{2}$ test, and quantitative data were compared using the unpaired $t$ test. A binomial multiple-variable logistic regression analysis was done to estimate risk of procedure-related complications, readmission, and refusion in patients who had degenerative kyphosis with SP compared with patients without SP. Variables that were significantly different on univariate analysis were included as covariates in the regression model. Additionally, we have used reimbursements associated with billable ICD codes to report cost of care associated with index hospital stay and 90-day hospital readmission for complications and refusion. The terms reimbursement, cost, and payment are used interchangeably throughout the text to represent the actual amount paid by Medicare.

\section{RESULTS}

A total of 2900 patients in 2 matched cohorts of 1450 each were included in our analysis. The number of patients for each age and gender group, region, comorbidity index, and year of surgery were the same in both groups (Table 1). In patients with $\mathrm{SP}$, the incidence of additional diagnoses was as follows: rheumatoid arthritis $(\mathrm{n}=862,59.5 \%)$, Parkinson's disease $(\mathrm{n}=267,18.4 \%)$, ankylosing spondylitis $(\mathrm{n}=165,11.4 \%)$, myopathy $(\mathrm{n}=90$, $6.2 \%)$, myasthenia gravis $(\mathrm{n}=40,2.8 \%)$, and hereditary or congenital muscular dystrophy $(\mathrm{n}=$ $26,1.8 \%$ ). Variation in procedure and hospitalrelated variables according to additional diagnoses have been given in Table 2 .

Patients undergoing fusion for cervical kyphosis with SP were more likely to have a posterior (26.8\% versus $21.5 \%$ ) or combined anterior-posterior fusion $(24.3 \%$ versus $19.0 \%)$; have surgery involving $\geq 8$ levels $(11.2 \%$ versus $3.8 \%)$ than patients with kyphosis without SP (all $P<.01$ ). Additionally, patients with SP had more patients with fusion extending to thoracic spine $(n=177,12.2 \%$ versus $n$

Table 2. Procedure and hospital-related variables according to diagnosis of secondary pathology (SP) in patients undergoing primary cervical fusion for degenerative kyphosis, Medicare (2005-2014).

\begin{tabular}{|c|c|c|c|c|c|c|}
\hline & $\begin{array}{c}\text { Rheumatoid } \\
\text { Arthritis }\end{array}$ & $\begin{array}{c}\text { Parkinson's } \\
\text { Disease }\end{array}$ & $\begin{array}{l}\text { Ankylosing } \\
\text { Spondylitis }\end{array}$ & Myopathy & $\begin{array}{c}\text { Myasthenia } \\
\text { Gravis }\end{array}$ & $\begin{array}{l}\text { Muscular } \\
\text { Dystrophy }\end{array}$ \\
\hline Total Patients $(\mathrm{N}=1450)$, no. $(\%)$ & $862(59.5)$ & $267(18.4)$ & $165(11.4)$ & $90(6.2)$ & $40(2.8)$ & $26(1.8)$ \\
\hline \multicolumn{7}{|l|}{ Fusion approach, no. (\%) } \\
\hline Anterior & $519(51.4)$ & $135(46.1)$ & $47(24.2)$ & $40(38.1)$ & $25(53.2)$ & $12(40.0)$ \\
\hline Posterior & $242(24.0)$ & $91(31.1)$ & $98(50.5)$ & $33(31.4)$ & $11(23.4)$ & $9(30.0)$ \\
\hline Anterior-Posterior & $249(24.7)$ & $67(22.9)$ & $49(25.3)$ & $32(30.5)$ & $11(23.4)$ & $9(30.0)$ \\
\hline \multicolumn{7}{|l|}{ levels of surgery, no. (\%) } \\
\hline $1-2$ & $409(40.5)$ & $105(33.7)$ & $56(29.8)$ & $31(29.5)$ & $23(48.9)$ & $16(53.3)$ \\
\hline $3-7$ & $548(54.2)$ & $169(54.1)$ & $110(58.5)$ & $58(55.2)$ & $17(36.2)$ & $13(43.3)$ \\
\hline$\geq 8$ & $54(5.3)$ & $38(12.2)$ & $22(11.7)$ & $16(15.2)$ & $7(14.9)$ & $1(3.3)$ \\
\hline Mean hospital payment $\pm \mathrm{SD}, \$$ & $27246 \pm 24060$ & $32715 \pm 31487$ & $31742 \pm 22348$ & $33004 \pm 26568$ & $27861 \pm 20882$ & $31787 \pm 31572$ \\
\hline Mean $\operatorname{LOS} \pm \mathrm{SD}, \mathrm{d}$ & $4.4 \pm 5.1$ & $6.1 \pm 7.0$ & $5.7 \pm 5.2$ & $5.5 \pm 5.1$ & $4.5 \pm 4.8$ & $4.8 \pm 6.0$ \\
\hline
\end{tabular}

Abbreviations: LOS, length of stay; SD, standard deviation. 
Table 3. Procedure-related variables in patients undergoing primary cervical fusion for degenerative kyphosis with and without secondary pathology (SP), Medicare (2005-2014)

\begin{tabular}{|c|c|c|c|}
\hline & Degenerative Kyphosis With SP & Degenerative Kyphosis Without SP & $P$ Value \\
\hline Total patients, no. $(\%)$ & $1450(100)$ & $1450(100)$ & \\
\hline \multicolumn{4}{|l|}{ Diagnosis, no. $(\%)$} \\
\hline With myelopathy & $903(62.3)$ & $859(59.2)$ & .09 \\
\hline Without myelopathy & $547(37.3)$ & $591(40.8)$ & \\
\hline \multicolumn{4}{|l|}{ Fusion approach } \\
\hline Anterior, no. $(\%)$ & $709(48.9)$ & $863(59.5)$ & $<.01$ \\
\hline Mean hospital payment $\pm \mathrm{SD}, \$$ & $15362 \pm 2460$ & $15306 \pm 1872$ & .6 \\
\hline Mean LOS \pm SD, d & $2.8 \pm 0.4$ & $2.7 \pm 0.7$ & $<.01$ \\
\hline Posterior, no. $(\%)$ & $389(26.8)$ & $312(21.5)$ & $<.01$ \\
\hline Mean hospital payment $\pm \mathrm{SD}, \$$ & $31179 \pm 7103$ & $26306 \pm 7066$ & $<.01$ \\
\hline Mean LOS $\pm S D, d$ & $6.6 \pm 1.1$ & $5.3 \pm 1.0$ & $<.01$ \\
\hline Anterior-posterior, no. (\%) & $352(24.3)$ & $275(19.0)$ & $<.01$ \\
\hline Mean hospital payment $\pm \mathrm{SD}, \$$ & $44217 \pm 8554$ & $43059 \pm 10449$ & .12 \\
\hline Mean LOS \pm SD, d & $7.0 \pm 0.9$ & $6.1 \pm 0.9$ & $<.01$ \\
\hline \multicolumn{4}{|l|}{ Levels of surgery } \\
\hline $1-2$, no. $(\%)$ & $540(37.2)$ & $632(45.1)$ & $<.01$ \\
\hline Mean hospital payment \pm SD, $\$$ & $18808 \pm 4782$ & $16700 \pm 2583$ & $<.01$ \\
\hline Mean LOS \pm SD, d & $3.4 \pm 0.7$ & $2.8 \pm 0.6$ & $<.01$ \\
\hline $3-7$, no. $(\%)$ & $747(51.5)$ & $715(51.1)$ & .8 \\
\hline Mean hospital payment $\pm \mathrm{SD}, \$$ & $27734 \pm 4376$ & $25376 \pm 5102$ & $<.01$ \\
\hline Mean LOS $\pm S D, d$ & $5.1 \pm 0.5$ & $4.4 \pm 0.7$ & $<.01$ \\
\hline$\geq 8$, no. $(\%)$ & $163(11.2)$ & $53(3.8)$ & $<.01$ \\
\hline Mean hospital payment $\pm \mathrm{SD}, \$$ & $45047 \pm 12934$ & $49050 \pm 14678$ & .05 \\
\hline Mean LOS $\pm \mathrm{SD}, \mathrm{d}$ & $7.8 \pm 2.5$ & $8.3 \pm 2.3$ & .2 \\
\hline \multicolumn{4}{|l|}{ Overall } \\
\hline Mean hospital payment $\pm \mathrm{SD}, \$$ & $26545 \pm 25968$ & $22991 \pm 21599$ & $<.01$ \\
\hline Mean LOS $\pm \mathrm{SD}, \mathrm{d}$ & $4.8 \pm 5.6$ & $3.9 \pm 4.5$ & $<.01$ \\
\hline \multicolumn{4}{|l|}{ Discharge disposition, no. (\%) } \\
\hline Home & $1114(76.8)$ & $1176(81.1)$ & .04 \\
\hline Skilled nursing care or rehabilitation & $243(16.8)$ & $172(11.9)$ & $<.01$ \\
\hline Home health aid & $93(6.4)$ & $102(7.0)$ & .5 \\
\hline
\end{tabular}

Abbreviations: LOS, length of stay; SD, standard deviation.

$=119,8.2 \%)$ and atlantoaxial spine $(\mathrm{n}=50,3.4 \%$ versus $\mathrm{n}=25,1.7 \%)$ than patients without $\mathrm{SP}(P<$ .01 for both). The total hospital reimbursement for primary cervical fusion for degenerative kyphosis with and without SP $(n=1450$ each $)$ was $\$ 39507410$ and $\$ 34315680$, respectively. The mean index hospital payment (\$26545 \pm \$25968 versus \$22 $991 \pm \$ 21599$ ) and length of stay (LOS; $4.8 \pm 5.6$ versus $3.9 \pm 4.5$ days) was significantly ( $P$ $<.01)$ higher in those patients who had kyphosis with SP than those without SP (Table 3).

The overall perioperative complication rate was $17.9 \%(260 / 1450)$ in patients with SP and $11.3 \%$ $(164 / 1450)$ in patients without SP $(P<.01)$. The incidence of posthemorrhagic anemia during index hospital stay was higher in patients with kyphosis and SP than patients without SP $(12.4 \%$ versus $7.2 \%, P<.01)$. Likewise, the occurrence of a diagnosis of acute respiratory failure was higher in patients with SP than without SP $(3.4 \%$ versus $2.2 \%, P=.03)$. The incidence of cardiac or nervous system complications, dural tear, and hematoma during index hospital stay was similar in both groups. Patients who experienced any perioperative complication had significantly higher index hospital costs and LOS (Table 4). After adjusting for difference in approach and number of levels, the risk of procedure-related complications was higher in patients with SP than patients without SP (odds ratio $[\mathrm{OR}]=1.47,95 \%$ confidence interval $[\mathrm{CI}]$, $1.18-1.83, P<.001)$. In the same regression model, posterior $(\mathrm{OR}=3.46,95 \% \mathrm{CI}, 2.62-4.59, P<.001)$, combined $(\mathrm{OR}=3.25,95 \%$ CI, 2.45-4.33, $P<$ $.001), 3-7$ level (OR $=1.29,95 \% \mathrm{CI}, 1.01-1.65, P=$ $.04)$, and $\geq 8$ level fusions (OR $=3.85,95 \%$ CI, 2.59 5.71, $P<.001)$ were also independent predictors of procedure-related complications.

Patients with kyphosis and SP had a preexisting diagnosis of dysphagia in $55(3.8 \%)$ as opposed to $34 / 1450(2.3 \%)$ patients without SP $(P=0.02)$. A new diagnosis of dysphagia within 90 days after surgery occurred in $160(11.0 \%)$ patients with kyphosis and SP compared with $132(9.1 \%)$ patients without $\mathrm{SP}(P=.08)$.

A total 152 patients were readmitted to the hospital within 90 days after cervical fusion for degenerative kyphosis without SP, giving a readmission rate of $10.5 \%$. In patients with SP, the 90 - 
Table 4. Procedure-related complications and associated costs after cervical fusion for degenerative kyphosis with and without secondary pathology (SP), Medicare (2005-2014)

\begin{tabular}{|c|c|c|c|}
\hline Complication During Index Procedure & $\begin{array}{l}\text { Degenerative Kyphosis With SP } \\
\qquad(\mathrm{n}=1450)\end{array}$ & $\begin{array}{l}\text { Degenerative Kyphosis Without SP } \\
\qquad(\mathrm{n}=1450)\end{array}$ & $P$ Value \\
\hline Posthemorrhagic anemia, no. (\%) & $180(12.4)$ & $105(7.2)$ & $<.01$ \\
\hline Acute respiratory failure, no. (\%) & $49(3.4)$ & $32(2.2)$ & .03 \\
\hline Hematoma, no. $(\%)$ & $13(0.9)$ & $11(0.8)$ & .7 \\
\hline Dural tear, no. $(\%)$ & $<11(<0.8)$ & $14(1.0)$ & $\mathrm{a}$ \\
\hline Cardiac complications, no. (\%) & $13(0.9)$ & $12(0.8)$ & .8 \\
\hline Nervous system complications, no. (\%) & $12(0.8)$ & $12(0.8)$ & 1 \\
\hline Index hospital payment (mean $\pm \mathrm{SE}), \$$ & $18622 \pm 1501^{\mathrm{b}, \mathrm{c}}$ & $14571 \pm 1481^{\mathrm{b}, \mathrm{c}}$ & .06 \\
\hline Index hospital LOS (mean $\pm \mathrm{SE}), \mathrm{d}$ & $3.7 \pm 0.4^{\mathrm{b}, \mathrm{c}}$ & $3.4 \pm 0.3^{\mathrm{b}, \mathrm{c}}$ & .6 \\
\hline
\end{tabular}

Abbreviation: LOS, length of stay; SE, standard error.

anadequate data for calculation.

${ }^{\mathrm{b}}$ Incremental value over overall cohort mean (adjusted for approach and levels of surgery).

${ }^{\mathrm{c}} P<.001$ versus cohort mean.

day readmission rate was higher $(\mathrm{n}=172,11.9 \%)$, but the difference was not statistically significant $(P$ $=.24)$. In patients with SP, a total of 245 readmission episodes occurred in 172 patients, giving a mean of 1.4 readmissions per patient. Similarly, 205 readmission episodes occurred in 152 patients without SP (mean $=1.3$ ). The cause of readmissions as determined by primary diagnosis field has been summarized in Table 5. On adjusted analysis, patients who underwent cervical fusion for degenerative kyphosis with SP were not associated with a higher risk of readmission than patients without $\mathrm{SP}(\mathrm{OR}=1.04,95 \% \mathrm{CI}, 0.82-1.32, P=.7)$. We found posterior $(\mathrm{OR}=2.30,95 \% \mathrm{CI}, 1.71-3.1$, $P<.001)$ and combined approach of fusion $(\mathrm{OR}=$ $2.01,95 \% \mathrm{CI}, 1.48-2.71, P<.001)$ to be significant independent predictors for readmission within 90 days.

Totals of $15(1.03 \%)$ and $14(0.97 \%)$ refusions within 90 days were done in patients with and without SP, respectively $(P=.85)$. The risk of refusion within 90 days in patients with SP was not higher on logistic regression analysis $(\mathrm{OR}=0.95$, 95\% CI, 0.45-2.0, $P=.9$ ). Hospital costs and associated LOS for 90-day readmission and refusion have been given in Table 6 .

Taking all hospital costs into consideration, 1450 patients who underwent cervical fusion for degenerative kyphosis with SP incurred a total of $\$ 48336691$ (mean $=\$ 33336$ ) over 90 days for index surgery, readmission, and refusion. The same number of patients who underwent cervical fusion for degenerative kyphosis but without associated SP had a total 90-day hospital cost burden of $\$ 40564669($ mean $=\$ 27976)$.

\section{DISCUSSION}

The understanding of cervical alignment and its clinical relevance has increased over the years. ${ }^{1,3}$ Cervical kyphosis is often a progressive deformity, and depending on severity, it can result in pain, myelopathy, radiculopathy, difficulty in horizontal gaze, swallowing dysfunction, and settling of chin on the chest. ${ }^{24}$ The costs associated with ACD surgery and its complications have not been described before. Ours is an analysis of 90-day complications and cost of primary cervical fusion for degenerative kyphosis based on ICD-9 terminology in the Medicare population. The mean

Table 5. The 90-day hospital readmission after cervical fusion for degenerative kyphosis with and without secondary pathology (SP), Medicare (2005-2014).

\begin{tabular}{|c|c|c|}
\hline Cause & $\begin{array}{c}\text { Degenerative Kyphosis With SP, } \\
\text { No., \% Total Patients } \\
\text { (\% Total Readmission Episodes } \\
\text { (\% })\end{array}$ & $\begin{array}{c}\text { Degenerative Kyphosis Without SP, } \\
\text { No., \% Total Patients } \\
(\% \text { Total Readmission Episodes } \\
\text { ( })\end{array}$ \\
\hline Urinary tract infection & $77,5.3(31.4)$ & $64,4.4(31.2)$ \\
\hline Myocardial infarction & $42,2.9(17.1)$ & $38,2.6(18.5)$ \\
\hline Wound dehiscence and infection & $36,2.5(14.7)$ & $22,1.5(10.7)$ \\
\hline Systemic infection and sepsis & $29,2.0(11.8)$ & $18,1.2(8.8)$ \\
\hline Instrumentation or implant complications & $20,1.4(8.2)$ & $20,1.4(9.8)$ \\
\hline Pneumonia & $19,1.3(7.8)$ & $23,1.6(11.2)$ \\
\hline Deep vein thrombosis and pulmonary embolism & $8,0.6(3.3)$ & $8,0.6(3.9)$ \\
\hline
\end{tabular}

${ }^{\mathrm{a}} \mathrm{n}=1450$.

$\mathrm{b}_{\mathrm{n}}=245$.

$\mathrm{c}_{\mathrm{n}}=205$. 
Table 6. Hospital payment and length of stay (LOS) for 90-day readmission and refusion after primary cervical fusion for degenerative kyphosis with and without secondary pathology (SP), Medicare (2005-2014).

\begin{tabular}{|c|c|c|c|}
\hline & $\begin{array}{l}\text { Degenerative Kyphosis With SP } \\
\qquad(\mathrm{n}=1450)\end{array}$ & $\begin{array}{c}\text { Degenerative Kyphosis Without SP } \\
(\mathrm{n}=1450)\end{array}$ & $P$ Value \\
\hline Hospital readmission, no. (\%) & $172(11.9)$ & $152(10.5)$ & 0.24 \\
\hline Total reimbursement, (mean $\pm \mathrm{SD}), \$$ & $7667395(24316 \pm 15955)$ & $5759313(25283 \pm 19856)$ & 0.6 \\
\hline LOS $($ mean $\pm S D), d$ & $12.2 \pm 7.9$ & $13.1 \pm 8.6$ & 0.3 \\
\hline Cervical refusion, no. $(\%)$ & $15(1.03)$ & $14(0.97)$ & 0.85 \\
\hline Total reimbursement, $($ mean $\pm \mathrm{SD}), \$$ & $1161886(52546 \pm 26865)$ & $489676(25092 \pm 9200)$ & $<0.01$ \\
\hline LOS $($ mean $\pm S D), d$ & $8.8 \pm 6.1$ & $5.9 \pm 3.2$ & 0.1 \\
\hline
\end{tabular}

hospital payment for primary cervical fusion in these patients ranged from $\$ 15306$ to $\$ 49050$ depending on the approach and number of levels of fusion. The 90-day hospital readmission and refusion rates were $10.5 \%$ and $\sim 1 \%$, respectively. Patients with cervical kyphosis who had additional diagnoses of inflammatory arthropathy, Parkinson's disease, or neuromuscular pathology were more likely to undergo a posterior or combined approach and $\geq 8$ levels of fusion. Additionally, these patients were at a higher risk for perioperative complications but not 90-day readmission. Higher 90-day costs were observed in patients with secondary diagnoses of cervical kyphosis.

Depending on severity and passive correctability of deformity, surgery for ACD may be performed anteriorly, posteriorly, or by combined approaches. ${ }^{1,3,24}$ A higher proportion of kyphotic patients in our analysis underwent posterior or combined anterior-posterior and $\geq 8$ levels of fusion if they had associated diagnoses of inflammatory arthropathy, Parkinson's disease, or neuromuscular disorders. This may reflect more severe cervical disease as is expected in patients with these diagnoses. ${ }^{4-11}$ Deformity that extends over many levels often requires a long posterior or combined approach to achieve alignment and stability. 1,3 Consequently, the overall hospital costs for index surgery were higher in these patients. Such a relation between cost and approach and number of levels of fusion has been found in previous analyses as well. ${ }^{20,25,26}$

We found a perioperative complication rate of $11.3 \%$, out of which posthemorrhagic anemia constituted $7.2 \%$ and acute respiratory failure $2.2 \%$. The perioperative complication rate was higher in patients with SP $(17.9 \%)$, which was significant on adjusted regression analysis as well. A higher risk for perioperative complications in patients with SP resulted in prolonged hospital stay and mean cost of up to $\$ 18622$ in addition to payment for index surgery. Greater risk of hemorrhagic anemia and respiratory complications after spine surgery in patients with rheumatoid arthritis, ${ }^{27,28}$ ankylosing spondylitis, ${ }^{29}$ and Parkinson's disease $e^{11,30,31}$ has been reported before. Patients with systemic inflammatory pathology, such as rheumatoid arthritis and ankylosing spondylitis, may have underlying anemia of chronic disease or coagulation abnormalities. Likewise, there may be deficits in pulmonary function in these patients, especially in ankylosing spondylitis. ${ }^{27-29}$ Additionally, the need for a combined approach for fusion and higher number of levels of surgery in patients with inflammatory or neuromuscular pathology can compound the risk of complications. A posterior or combined approach and increasing number of levels of cervical fusion have been found to increase the risk of postoperative complications in previous studies as well. ${ }^{1,15,16,28,32}$ Given these findings, there is a need for consensus guidelines on approach, osteotomy, and levels of fusion, as marked variation in treatment plans for ACD among deformity surgeons have been found. ${ }^{12}$

While studies have reported early and late complications after ACD surgery, the incidence of hospital readmission has not been reported before. ${ }^{2,13,15,16}$ Difference in definitions and reporting of complications precludes direct comparison with literature. However, we believe that our comparison of complications and readmission between matched cohorts using the same definitions provides useful information on relative incidence and risk. In patients without SP, the 90-day readmission rate was $10.5 \%$ with most patients being admitted for urinary tract infection. While the overall rate of readmission between patients with and without SP $(11.9 \%$ versus $10.5 \%)$ did not differ significantly, more patients with SP were readmitted for wound and systemic infections. These findings may reflect immune deficiencies in patients with inflammatory arthropathy due to disease itself or disease-modifying treatment agents. ${ }^{27,29} \mathrm{~A}$ similar relation between rheumatoid arthritis and postoperative infection has been reported after total joint arthroplasty. ${ }^{33,34}$ 
Higher rates of infection after scoliosis surgery in patients with Parkinson's disease and other neuromuscular pathologies have been reported before. ${ }^{11,35}$ While it is known that patients with SP are associated with higher risk of instrumentation complications after thoracolumbar fusion due to poor bone quality, muscular imbalance, risk of falls, etc, ${ }^{8,11,36}$ our results did not find a difference. This may be due to analysis limited to 90 days or differences in mechanisms of instrumentation failure between surgery for cervical deformity and thoracolumbar or global malalignment. The approach of fusion rather than presence of SP was predictive of a higher risk of overall 90-day readmission in our adjusted analysis. Each readmission on average was reimbursed up to $\$ 25283 \pm 19956$ and resulted in an average of $13.1 \pm 8.6$ days of hospital stay.

There are several limitations to our analysis. First, this is a retrospective study using insurance claims data. There is potential for bias due to inaccuracy in coding methodology, missing data, or both. However, given that published studies on ACD surgery are reports with small patient cohorts, we believe that analysis of thousands of patients from claims data is beneficial. Although we have used specific ICD codes for cervical deformity to create our patient cohorts, we cannot confirm actual clinical diagnosis of cervical kyphosis and deformity. We were unable to study clinical information, such as severity of kyphosis, severity and treatment of SP, imaging features, operative time, blood loss, and patient reported outcomes. We were also unable to study the type and magnitude of kyphosis correction undertaken. For similar reasons, it is not possible to be certain that all patients had surgery to address deformity, especially in those undergoing 1-2 level fusions. However, our data still provide a comparison between cervical fusion in patients with and without SP. Lastly, we were unable to study outpatient costs as our database has outpatient and physician billing (CPT) from a 5\% national sample and not $100 \%$ Medicare. We also did not have access to drug prescription data. While these would be beneficial to study, most costs from elective spine surgery are driven by hospital, complications, and readmission. ${ }^{20,25}$ Despite these limitations, we have described the incidence and costs of 90-day complications and readmissions after cervical fusion for kyphosis in a large Medicare population. We have also described how the presence of inflammatory pathology and neuromus- cular disorders affect the complication and cost profile.

\section{CONCLUSIONS}

Index hospital payment for cervical fusion for degenerative kyphosis primarily depends on approach and number of levels of fusion. From an overall health care perspective, patients with cervical kyphosis in the presence of a secondary diagnosis of inflammatory arthropathy or neuromuscular pathology incur higher 90-day costs due to inherent requirement of bigger fusions and higher risk of perioperative complications, but with similar risk of readmission and refusion as patients without such additional pathology. This information will be important to providers for preoperative counselling of patients on risk of complications. Additionally, the knowledge of conditions associated with higher costs after elective cervical spine surgery will be important for providers and payors to incorporate risk adjustment in future payment reforms and models in such patients.

\section{REFERENCES}

1. Hann S, Chalouhi N, Madineni R, et al. An algorithmic strategy for selecting a surgical approach in cervical deformity correction. Neurosurg Focus. 2014;36(5):E5.

2. Smith JS, Ramchandran S, Lafage V, et al. Prospective multicenter assessment of early complication rates associated with adult cervical deformity surgery in 78 patients. Neurosurgery. 2016;79(3):378-388.

3. Scheer JK, Tang JA, Smith JS, et al. Cervical spine alignment, sagittal deformity, and clinical implications: a review. J Neurosurg Spine. 2013;19(2):141-159.

4. Yoshiyama Y, Takama J, Hattori T. The dropped head sign in parkinsonism. $J$ Neurol Sci. 1999;167(1):22-25.

5. Kim HJ, Nemani VM, Riew KD, et al. Cervical spine disease in rheumatoid arthritis: incidence, manifestations, and therapy. Curr Rheumatol Rep. 2015;17(2):9. doi:10.1007/s11926014-0486-8

6. Nguyen HV, Ludwig SC, Silber J, et al. Rheumatoid arthritis of the cervical spine. Spine J. 2004;4(3):329-334.

7. Etame AB, Than KD, Wang AC, et al. Surgical management of symptomatic cervical or cervicothoracic kyphosis due to ankylosing spondylitis. Spine (Phila Pa 1976). 2008;33(16):E559-E564.

8. Sharan AD, Kaye D, Charles Malveaux WM, et al. Dropped head syndrome: etiology and management. $J \mathrm{Am}$ Acad Orthop Surg. 2012;20(12):766-774.

9. Suarez GA, Kelly JJ. The dropped head syndrome. Neurology. 1992;42(8):1625-1627.

10. Petheram TG, Hourigan PG, Emran IM, et al. Dropped head syndrome: a case series and literature review. Spine (Phila Pa 1976). 2008;33(1):47-51.

11. Protopsaltis TS, Boniello AJ, Schwab FJ. Management 
of spinal deformity in adult patients with neuromuscular disease. J Am Acad Orthop Surg. 2016;24(9):634-644.

12. Smith JS, Klineberg E, Shaffrey CI, et al. Assessment of surgical treatment strategies for moderate to severe cervical spinal deformity reveals marked variation in approaches, osteotomies, and fusion levels. World Neurosurg. 2016;91:228237.

13. Etame AB, Wang AC, Than KD, et al. Outcomes after surgery for cervical spine deformity: review of the literature. Neurosurg Focus. 2010;28(3):E14. doi:10.3171/2010.1. FOCUS09278

14. Smith JS, Shaffrey CI, Kim HJ, et al. Prospective multicenter assessment of all-cause mortality following surgery for adult cervical deformity. Neurosurgery. 2018;83(6):12771285.

15. Passias PG, Horn SR, Jalai CM, et al. Comparative analysis of perioperative complications between a multicenter prospective cervical deformity database and the Nationwide Inpatient Sample database. Spine J. 2017;17(11):1633-1640.

16. Grosso MJ, Hwang R, Krishnaney AA, et al. Complications and outcomes for surgical approaches to cervical kyphosis. J Spinal Disord Tech. 2015;28(7):E385-E393.

17. Zygourakis CC, Liu CY, Keefe M, et al. Analysis of national rates, cost, and sources of cost variation in adult spinal deformity. Neurosurgery. 2018;82(3):378-387.

18. Raman T, Nayar SK, Liu S, et al. Cost-effectiveness of primary and revision surgery for adult spinal deformity. Spine (Phila Pa 1976). 2018;43(11):791-797.

19. Qureshi R, Puvanesarajah V, Jain A, et al. Cost implications of primary versus revision surgery in adult spinal deformity. World Neurosurg. 2017;104:68-73.

20. Jain N, Phillips FM, Khan SN. Distribution and determinants of 90-day payments for multilevel posterior lumbar fusion: a Medicare analysis. Clin Spine Surg. 2018;31(3):E197-E203.

21. Charlson M, Szatrowski TP, Peterson J, et al. Validation of a combined comorbidity index. $J$ Clin Epidemiol. 1994;47(11):1245-51.

22. PearlDiver Technologies, Inc. http://pearldiverinc.com/. Accessed May 2, 2020.

23. Bundled Payments for Care Improvement (BPCI) initiative: general information. https://innovation.cms.gov/ initiatives/bundled-payments/. Accessed March 18, 2019.

24. O'Shaughnessy BA, Liu JC, Hsieh PC, et al. Surgical treatment of fixed cervical kyphosis with myelopathy. Spine (Phila Pa 1976). 2008;33(7):771-778.

25. Virk SS, Phillips FM, Khan SN. Bundled payment reimbursement for anterior and posterior approaches for cervical spondylotic myelopathy: an analysis of private payer and Medicare databases. J Neurosurg Spine. 2018;28(3):244251.

26. Shamji MF, Cook C, Pietrobon R, et al. Impact of surgical approach on complications and resource utilization of cervical spine fusion: a nationwide perspective to the surgical treatment of diffuse cervical spondylosis. Spine J. 2009;9(1):3138.

27. Ohya J, Chikuda H, Kato S, et al. Risks of in-hospital death and complications after fusion surgery in patients with atlantoaxial subluxation: analysis of 1090 patients using the
Japanese Diagnosis Procedure Combination Database. World Neurosurg. 2015;83(4):603-607.

28. Passias PG, Diebo BG, Marascalchi BJ, et al. A novel index for quantifying the risk of early complications for patients undergoing cervical spine surgeries. J Neurosurg Spine. 2017;27(5):501-507.

29. Robinson Y, Robinson AL, Olerud C. Complications and survival after long posterior instrumentation of cervical and cervicothoracic fractures related to ankylosing spondylitis or diffuse idiopathic skeletal hyperostosis. Spine (Phila Pa 1976). 2015;40(4):E227-E233.

30. De la Garza Ramos R, Goodwin CR, Jain A, et al. Inpatient morbidity after spinal deformity surgery in patients with movement disorders. J Spine Surg. 2017;3(4):601-608.

31. Baker JF, McClelland S 3rd, Line BG, et al. In-hospital complications and resource utilization following lumbar spine surgery in patients with Parkinson disease: evaluation of the National Inpatient Sample Database. World Neurosurg. 2017; 106:470-476.

32. Cole T, Veeravagu A, Zhang M, et al. Anterior versus posterior approach for multilevel degenerative cervical disease: a retrospective propensity score-matched study of the MarketScan Database. Spine (Phila Pa 1976). 2015;40(13):1033-1038.

33. Bongartz T, Halligan CS, Osmon DR, et al. Incidence and risk factors of prosthetic joint infection after total hip or knee replacement in patients with rheumatoid arthritis. Arthritis Rheum. 2008;59(12):1713-1720.

34. Ravi B, Croxford R, Hollands S, et al. Increased risk of complications following total joint arthroplasty in patients with rheumatoid arthritis. Arthritis Rheumatol. 2014;66(2):254-263.

35. Duckworth AD, Mitchell MJ, Tsirikos AI. Incidence and risk factors for post-operative complications after scoliosis surgery in patients with Duchenne muscular dystrophy: a comparison with other neuromuscular conditions. Bone Joint J. 2014;96-B(7):943-949.

36. Arima H, Glassman SD, Dimar JR 2nd, Matsuyama Y, Carreon LY. Neurologic comorbidities predict proximal junctional failure in adult spinal deformity. Spine Deform. 2018;6(5):576-586.

Disclosures and COI: The authors received no funding for this study. Institutional review board approval was not required for this study.

Corresponding Author: Elizabeth Yu, MD, Department of Orthopaedics, The Ohio State University Wexner Medical Center, 725 Prior Hall, Columbus, OH 43210. Phone: (614) 293-2165; Fax: (614) 293-4755; Email: Elizabeth.Yu@osumc.edu.

Published 26 February 2021

This manuscript is generously published free of charge by ISASS, the International Society for the Advancement of Spine Surgery. Copyright (C) 2021 ISASS. To see more or order reprints or permissions, see http://ijssurgery.com. 
Jain et al.

Table A1. Definitions of International Classification of Diseases, 9th revision (ICD-9) codes for inclusion and exclusion of study cohort. Primary Cervical Fusion for Cervical Deformity. Medicare (2005-2014).

\begin{tabular}{|c|c|}
\hline \multicolumn{2}{|c|}{ Cervical Degenerative Diagnosis } \\
\hline ICD-9-D-7211 & Cervical spondylosis with myelopathy \\
\hline ICD-9-D-7210 & Cervical spondylosis without myelopathy \\
\hline ICD-9-D-7230 & Spinal stenosis in cervical region \\
\hline ICD-9-D-7224 & Degeneration of cervical intervertebral disc \\
\hline ICD-9-D-72271 & Intervertebral disc disorder with myelopathy, cervical region \\
\hline ICD-9-D-7220 & Displacement of cervical intervertebral disc without myelopathy \\
\hline ICD-9-D-7231 & Cervicalgia \\
\hline \multicolumn{2}{|c|}{ Coexisting or previous ICD Diagnosis and Procedures - EXCLUSION } \\
\hline ICD-9-D-1702 & Malignant neoplasm of vertebral column excluding sacrum and coccyx \\
\hline ICD-9-D-2132 & Benign neoplasm of vertebral column, excluding sacrum and coccyx \\
\hline ICD-9-D-0150 & Tuberculosis of vertebral column \\
\hline ICD-9-D-73008 & Acute osteomyelitis other specified sites \\
\hline ICD-9-D-73028 & Unspecified osteomyelitis other specified sites \\
\hline ICD-9-D-73313 & Pathologic fracture of vertebrae \\
\hline ICD-9-D-80500 & Closed fracture of cervical vertebra unspecified level \\
\hline ICD-9-D-80501 & Closed fracture of first cervical vertebra \\
\hline ICD-9-D-80502 & Closed fracture of second cervical vertebra \\
\hline ICD-9-D-80504 & Closed fracture of fourth cervical vertebra \\
\hline ICD-9-D-80505 & Closed fracture of fifth cervical vertebra \\
\hline ICD-9-D-80506 & Closed fracture of sixth cervical vertebra \\
\hline ICD-9-D-80507 & Closed fracture of seventh cervical vertebra \\
\hline ICD-9-D-80508 & Closed fracture of multiple cervical vertebrae \\
\hline ICD-9-D-8052 & Closed fracture of dorsal [thoracic] vertebra without mention of spinal cord injury \\
\hline ICD-9-D-80600 & Closed fracture of $\mathrm{C} 1-\mathrm{C} 4$ level with unspecified spinal cord injury \\
\hline ICD-9-D-80605 & Closed fracture of $\mathrm{C} 5-\mathrm{C} 7$ level with unspecified spinal cord injury \\
\hline ICD-9-D-80606 & Closed fracture of C5-C7 level with complete lesion of cord \\
\hline ICD-9-D-80608 & Closed fracture of C5-C7 level with central cord syndrome \\
\hline ICD-9-D-80609 & Closed fracture of C5-C7 level with other specified spinal cord injury \\
\hline ICD-9-P-0353 & Repair of vertebral fracture \\
\hline ICD-9-P-8106 & Lumbar and lumbosacral fusion of the anterior column, anterior technique \\
\hline ICD-9-P-8107 & Lumbar and lumbosacral fusion of the posterior column, posterior technique \\
\hline ICD-9-P-8108 & Lumbar and lumbosacral fusion of the anterior column, posterior technique \\
\hline \multicolumn{2}{|l|}{ Kyphosis } \\
\hline ICD-9-D-73710 & Kyphosis (acquired) (postural) \\
\hline ICD-9-D-73719 & Kyphosis associated with other conditions \\
\hline ICD-9-D-73741 & Other kyphosis (acquired) \\
\hline \multicolumn{2}{|c|}{ Secondary causes of severe cervical deformity } \\
\hline ICD-9-D-7140 & Rheumatoid arthritis \\
\hline ICD-9-D-7142 & Other rheumatoid arthritis with visceral or systemic involvement \\
\hline ICD-9-D-7200 & Ankylosing spondylitis \\
\hline ICD-9-D-3320 & Paralysis agitans \\
\hline ICD-9-D-3321 & Secondary parkinsonism \\
\hline ICD-9-D-35800 & Myasthenia gravis without (acute) exacerbation \\
\hline ICD-9-D-3590 & Congenital hereditary muscular dystrophy \\
\hline ICD-9-D-3591 & Hereditary progressive muscular dystrophy \\
\hline
\end{tabular}


Table A2. Definitions of International Classification of Diseases, 9th revision (ICD-9) codes for complications, primary diagnosis field in readmitted patients, and refusion. Cervical Fusion for Cervical Deformity. Medicare (2005-2014).

\begin{tabular}{|c|c|}
\hline \multicolumn{2}{|c|}{ Procedure-Related Complications } \\
\hline ICD-9-D-2851 & Acute posthemorrhagic anemia \\
\hline ICD-9-D-99709 & Other nervous system complications \\
\hline ICD-9-D-9971 & Cardiac complications not elsewhere classified \\
\hline ICD-9-D-51881 & Acute respiratory failure \\
\hline ICD-9-D-99812 & Hematoma complicating a procedure \\
\hline ICD-9-D-9982 & Accidental puncture or laceration during a procedure not elsewhere classified \\
\hline \multicolumn{2}{|l|}{ Dysphagia } \\
\hline ICD-9-D-78720 & Dysphagia unspecified \\
\hline ICD-9-D-78722 & Dysphagia oropharyngeal phase \\
\hline ICD-9-D-78723 & Dysphagia pharyngeal phase \\
\hline ICD-9-D-78729 & Other dysphagia \\
\hline \multicolumn{2}{|c|}{ Primary Diagnosis in Readmitted Patients } \\
\hline \multicolumn{2}{|c|}{ Wound Infection and Dehiscence } \\
\hline ICD-9-D-99667 & Infection and inflammatory reaction due to other internal orthopedic device implant and graft \\
\hline ICD-9-D-99831 & Disruption of internal operation (surgical) wound \\
\hline ICD-9-D-99832 & Disruption of external operation (surgical) wound \\
\hline ICD-9-D-99859 & Other postoperative infection \\
\hline \multicolumn{2}{|c|}{ Systemic Infection and Sepsis } \\
\hline ICD-9-D-00845 & Intestinal infection due to Clostridium difficile \\
\hline ICD-9-D-0380 & Streptococcal septicemia \\
\hline ICD-9-D-03811 & Methicillin susceptible Staphylococcus aureus septicemia \\
\hline ICD-9-D-03840 & Septicemia due to gram-negative organism unspecified \\
\hline ICD-9-D-03849 & Other septicemia due to gram-negative organisms \\
\hline ICD-9-D-0389 & Unspecified septicemia \\
\hline ICD-9-D-3241 & Intraspinal abscess \\
\hline \multicolumn{2}{|l|}{ Pneumonia } \\
\hline ICD-9-D-48282 & Pneumonia due to escherichia coli [E. coli] \\
\hline ICD-9-D-486 & Pneumonia organism unspecified \\
\hline ICD-9-D-99732 & Postprocedural aspiration pneumonia \\
\hline \multicolumn{2}{|c|}{ Myocardial Infarction } \\
\hline ICD-9-D-41071 & Subendocardial infarction initial episode of care \\
\hline ICD-9-D-4111 & Intermediate coronary syndrome \\
\hline ICD-9-D-4139 & Other and unspecified angina pectoris \\
\hline ICD-9-D-41401 & Coronary atherosclerosis of native coronary artery \\
\hline \multicolumn{2}{|c|}{ Urinary Tract Infection } \\
\hline ICD-9-D-5990 & Urinary tract infection site not specified \\
\hline \multicolumn{2}{|c|}{ Deep Vein Thrombosis and/or Pulmonary Embolism } \\
\hline ICD-9-D-41519 & Other pulmonary embolism and infarction \\
\hline ICD-9-D-45351 & Chronic venous embolism and thrombosis of deep vessels of proximal lower extremity \\
\hline \multicolumn{2}{|c|}{ Mechanical Complications of Instrumentation and Implants } \\
\hline ICD-9-D-99640 & Unspecified mechanical complication of internal orthopedic device implant and graft \\
\hline ICD-9-D-99649 & Other mechanical complication of other internal orthopedic device implant and graft \\
\hline ICD-9-D-99659 & Mechanical complication due to other implant and internal device not elsewhere classified \\
\hline \multicolumn{2}{|l|}{ Cervical Refusion } \\
\hline ICD-9-P-8132 & Refusion of other cervical spine anterior column anterior technique \\
\hline ICD-9-P-8133 & Refusion of other cervical spine posterior column posterior technique \\
\hline
\end{tabular}

